\title{
PHOTOCHEMICAL PARTICULATE FORMATION IN SULFUR DIOXIDE-AIR MIXTURES
}

\author{
Chi-Hung Shen and George S. Springer \\ Department of Mechanical Engineering. The University of Michigan. Ann Arbor, MI, U.S.A.
}

(First received 21 July 1975 and in final form 28 August 1975)

\begin{abstract}
Experiments were performed studying the formation of particulates in sulfur dioxide-air mixtures irradiated by ultraviolet light. Measurements were made for five different initial sulfur dioxide concentrations $(0.2,0.3,0.5,0.7$ and $1 \mathrm{ppm})$ and for four relative humidities $(25,50,75$ and $100 \%)$. The data show that the maximum number of nuclei (particles smaller than $0.1 \mu \mathrm{m}$ ) produced in the mixture is proportional to the initial sulfur dioxide concentration and to the square of the relative humidity. Particles larger than $0.3 \mu \mathrm{m}$ were not present in measurable amounts in the mixturc.
\end{abstract}

\section{INTRODUCTION}

The formation of particles in sulfur dioxide-air mixtures irradiated by ultraviolet light has been studied widely (see, e.g. Shen and Springer, 1975a). However, the number of particulates formed and the dependence of this number on the initial sulfur dioxide concentration and on the humidity of the air are not yet well established. The objectives of this investigation were, therefore, to measure the number of particulates formed in sulfur dioxide-air mixtures and to determine the relationships between the number of particulates formed, the initial sulfur dioxide concentration, and the relative humidity of the air.

\section{EXPERIMENTAL}

The experimental apparatus and procedure were given elsewhere (Shen et al., 1975; Shen and Springer, 1975a. b) and will not be described here in detail. Only those aspects of the cxperiment are presented which directly facilitate the understanding of the results.

The photochemical reactions were generated in a $9 \mathrm{~m}$ long. $15.2 \mathrm{~cm}$ i.d. Pyrex tube arranged horizontally in a straight line ("tunnel" in Fig. 1). Several openings were made in the wall of the tube for inserting sampling probes, these openings being located on top of the tube. The present experiments utilized only the first opening. $23 \mathrm{~cm}$ from the entrance of the tunnel. A $30.4 \mathrm{~cm}$ long, $15.2 \mathrm{~cm}$ i.d. stainless steel chamber was connected to the upstream end

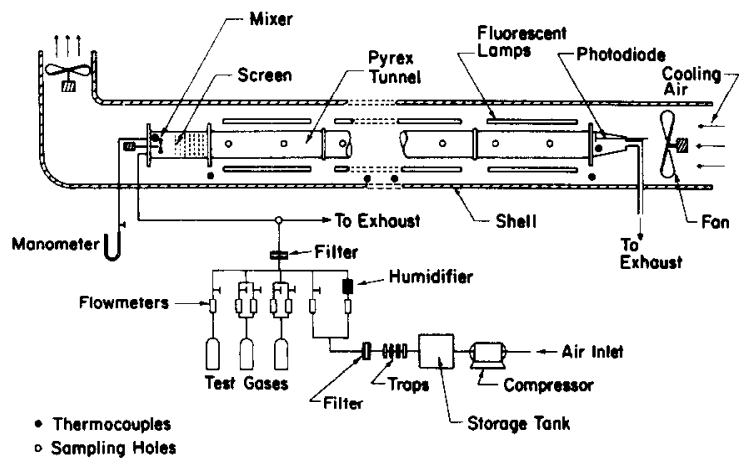

Fig. 1. Schematic of experimental apparatus. of the tunnel. The gas air mixture inside this chamber was stirred by a fan. Stainless steel screens serving as flow straighteners were placed downstream of the fan. The downstream end of the tunnel was connected to an exhaust vent. During the tests the pressure was practically atmospheric throughout the tunnel.

The u.v. radiation was produced by forty-eight $\mathrm{F} 40 \mathrm{BL}$ (General Electric) fluorescent lamps arranged in six clusters along the tunnel. Each cluster contained eight lamps placed around the tunnel symmetrically on a $31.7 \mathrm{~cm}$ dia. circle. The lamps were mounted on two semicircular metal shells covered on the inside with aluminum foil. Room air was blown through the annulus between the tunnel and the shell in the direction opposite to the flow inside the tunnel. The maximum temperature rise of the cooling air was $7^{\circ} \mathrm{C}$. The temperature rise of the gas-air mixture along the tunnel was always less than $4^{\circ} \mathrm{C}$.

The total intensity and the spectral distribution of the u.v. light inside the tunnel were monitored by a photodiode and a monochromator, respectively. These instruments did not provide directly the light intensity and the spectral distribution. Their outputs were monitored to ascertain that the light intensity and the spectral distribution remained constant throughout the tests. The total light intensity was characterized by the photolysis rate constant of nitrogen dioxide $k_{1}$. For the present apparatus $k_{1}$ was found to be $k_{1}=6.33 \mathrm{k} \mathrm{s}^{-1}$ (Shen et al., 1975). This $k_{1}$ value is similar to those which exist in the lower atmosphere; it also compares well with the values used in previous experiments (Shen and Springer, 1975a).

The air used in the experiments was supplied from an air-conditioned room by an oil-free, diaphragm type compressor. The air was passed through a series of drying agents and filters and was then branched into two streams. One stream was designated as "dry air", while the other stream passed through a humidifier where it was saturated with water vapor. The two streams were then joined together. The relative humidity of the test air was controlled by adjusting the flowrates of the two streams of air.

The sulfur dioxide was prediluted with pure dry nitrogen to approximately $200 \mathrm{ppm}$ by the manufacturer. The flowrates of the air and the sulfur dioxide were regulated by stainless steel needle valves and were measured by flowmeters. Beyond the flowmeters the air and gas lines were joined. The mixture then passed through a Gelman type A glass fiber filter and entered the mixing chamber.

The sampling probe was made of $0.486 \mathrm{~cm}$ i.d., $0.636 \mathrm{~cm} \mathrm{o.d.} \mathrm{and} 30 \mathrm{~cm}$ long stainless steel tubing (Fig. 2). Twelve $0.223 \mathrm{~cm}$ dia. holes were drilled into the probe, six holes being on one side of the probe and six on 


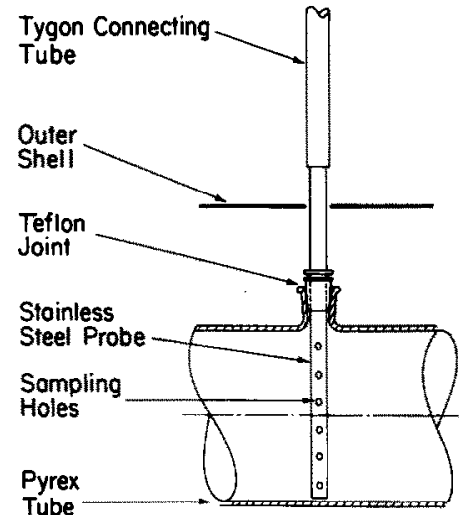

Fig. 2. Schematic of the sampling probe.

the opposite side. The first two holes were $1.27 \mathrm{~cm}$ from the tip of the probe. The distance between each subsequent pair of holes was $2.54 \mathrm{~cm}$. One end of the probe was sealed. The probe was mounted vertically so that the closed tip was touching the bottom of the tunnel. The axes of the sampling holes were normal to the direction of the flow, i.e. the holes faced the walls of the tunnel. The open end of the probe was outside the tunnel and was connected to the particulate measuring instruments.

The particles were examined in two different categories. The first category consisted of those particles whose diameters were between $2 \mathrm{~nm}$ and $0.1 \mu \mathrm{m}$. These particles were designated as condensation nuclei and were measured by a condensation nuclei counter (Gardner Associates "Small-Particle Detector"). In the second category were those particles whose diameters were greater than $c a .0 .3$ $\mu \mathrm{m}$. These particles were designated as aerosols and were measured hy a Model 225 Royco Particle Counter. The number concentrations ( $\mathrm{No} . \mathrm{cm}^{-3}$ ) of both the condensation nuclei and the aerosols were measured during the experiments. The maximum error in the data was estimated to be $c a . \pm 40 \%$ (Shen and Springer, 1975a). To minimize the error caused by statistical fluctuations, every measurement was repeated at least three times. The data points shown are the averages of the measured values.

At the start of each series of tests the u.v. lamps were turned on and $50 \%$ r.h. air (without sulfur dioxide in it) was fed through the tunnel continuously until the nuclei and aerosol counters indicated zero readings along the tunnel. This condition was usually reached in four to seven days. The required sulfur dioxide-air mixture was then introduced into the tunnel. The nuclei and aerosol contents were measured after their values stabilized along the entire length of the tunnel.

\section{RESULTS}

When the sulfur dioxide-air mixture was exposed in the tunnel to u.v. radiation the number of particulates increased with time until it reached a maximum value (Fig. 3). Here we were interested in the maximum number of particulates formed in the mixture. In order to determine the exposure time required to reach the maximum number of particulates, the number of nuclei and aerosols were measured at sampling station No. 1 at different flowrates ranging from $46 \mathrm{~cm}^{3} \mathrm{~s}^{-1}$ to $184 \mathrm{~cm}^{3} \mathrm{~s}^{-1}$. Since sampling station No. 1 was $23 \mathrm{~cm}$ from the entrance to the tunnel, the exposure times corresponding to these flowrates ranged from 90 to $22.7 \mathrm{~s}$. The experiments were repeated for different sulfur dioxide concentrations and different humidities (Fig. 3). There were no measurable amounts of aerosols (i.e. particles larger than 0.3 $\mu \mathrm{m})$ in any of the experiments. Nuclei, however, were found in the mixture. The amount of nuclei depended on the exposure time, as shown in Fig. 3. The time required to reach the maximum number of nuclei increased as both the initial sulfur dioxide concentration and the initial relative humidity in the air decreased. The term "initial" refers $w$ conditions at the entrance of the tunnel, i.e. before the mixture was exposed to the u.v. light. The initial sulfur dioxide concentration and the initial relative humidity are denoted by $\left[\mathrm{SO}_{2}\right]_{0}$ and $[\phi]_{0}$, respectively.

The lowest initial sulfur dioxide concentration used in the experiment was 0.2 and the lowest $t h$. was $25 \%$. For this condition the time required to form the maximum number of nuclei was about $90 \mathrm{~s}$. Therefore, to ensure that the maximum number of nuclei was reached in all the tests, the $90 \mathrm{~s}$ exposure time was used throughout the subsequent experiments. The number of nuclei $\mathrm{cm}^{-3}$ given below corresponds to the maximum value obtained in the manner just described.

The effects of the initial sulfur dioxide concentration and the initial relative humidity on the nuclei formation were measured for five different sulfur dioxide concentrations $\left(\left[\mathrm{SO}_{2}\right]_{0}=0.2,0.3,0.5,0.7\right.$ and $1 \mathrm{ppm})$ and four different relative humidities $\left([\phi]_{0}=25,50,75\right.$ and $100 \%$. The data, presented

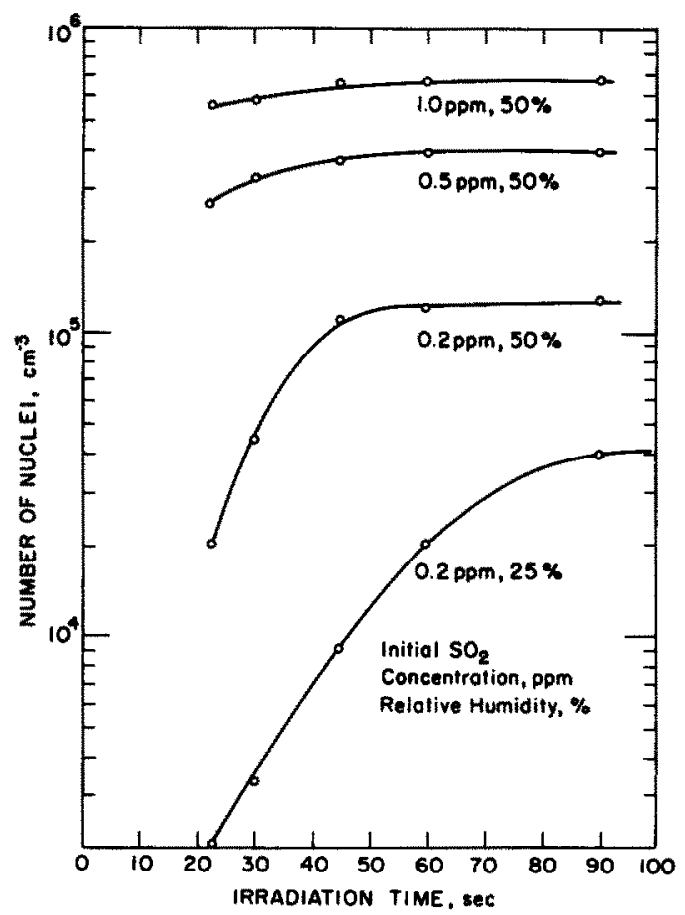

Fig. 3. Number of nuclei formed as a function of irradiation time in sulfur dioxide-air mixtures. 


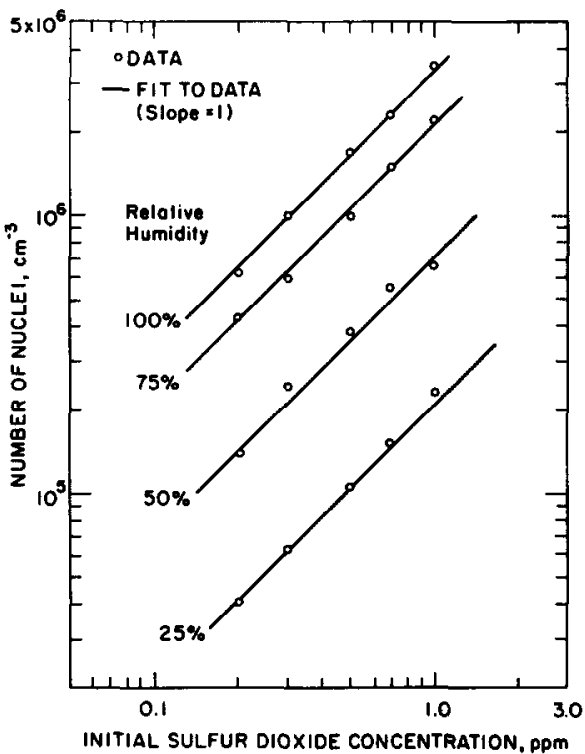

Fig. 4. Number of nuclei formed in sulfur dioxide-air mixtures.

in Fig. 4, indicate that the number of nuclei vary linearly with the initial sulfur dioxide concentration in the air.

The results in Fig. 4 were cross plotted in order to obtain directly the variation of the number of nuclei with relative humidity. As shown in Fig. 5, the number of nuclei varies with the square of the relative humidity. Thus, according to the results of Figs. 4 and 5 , the maximum number of nuclei formed may be expressed as

$$
N=A\left[\mathrm{SO}_{2}\right]_{0}[\phi]_{0}^{2} \mathrm{~cm}^{-3},
$$

where $A$ is a constant. In order to test further the validity of equation (1) and to obtain the value of

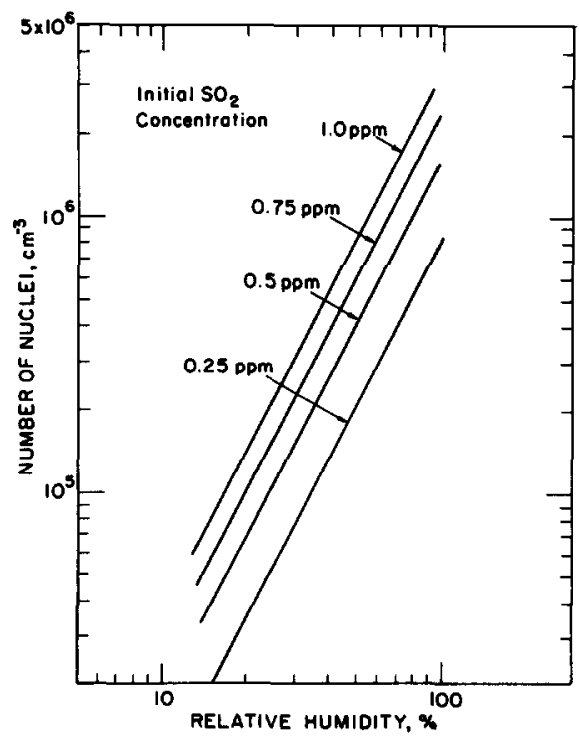

Fig. 5. Number of nuclei formed in sulfur dioxide-air mixtures.

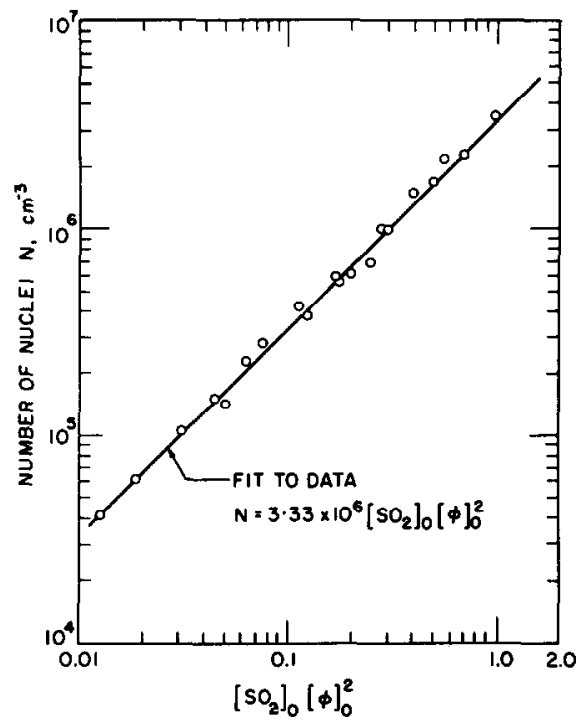

Fig. 6. Number of nuclei formed in sulfur dioxide -air mixtures. Correlation of the data for various initial sulfur dioxide concentrations $\left[\mathrm{SO}_{2}\right]_{0}$ and initial relative humidities $[\phi]_{0}$.

$A$, all the data were compiled on a $N$ vs $\left[\mathrm{SO}_{2}\right]_{0}[\phi]_{0}^{2}$ plot (Fig. 6). The data correlated well with the above expression for $A=3.33 \times 10^{6} \mathrm{~cm}^{-3} \mathrm{ppm}^{-1}$. Thus, the maximum number of nuclei is given by the expression

$$
N=3.33 \times 10^{6}\left[\mathrm{SO}_{2}\right]_{0}[\phi]_{0}^{2} \mathrm{~cm}^{3},
$$

where $\left[\mathrm{SO}_{2}\right]_{0}$ is in ppm and $[\phi]_{0}$ is in per cent.

It should be noted that equation (2) was determined from the data obtained under specific experimental conditions. The light intensity inside the tunnel was not varied during these experiments. Hence, equation (2) does not indicate the effect of the light intensity on nuclei production. Groblicki and Nebel (1971) found that the maximum amount of aerosols produced in a propylene-nitric oxide-sulfur dioxide-air mixture was not affected by a change in the light intensity. The light intensity merely affected the time required to produce the maximum number of nuclei. The effect of light intensity on the nuclei formation should be investigated further.

In order to describe the foregoing results quantitatively it would be necessary to know in detail the reaction mechanisms in the mixture. Unfortunately, the precise mechanism of the photooxidization of sulfur dioxide is not known. Nevertheless, it is possible to explain, at least qualitatively, the nuclei formation in sulfur dioxide air mixtures by referring to the simplified kinetic scheme presented by Leighton (1961). According to this scheme, at large oxygen concentrations, the primary mechanism involving activated molecules is

$$
\begin{gathered}
\mathrm{SO}_{2}+h v \rightarrow \mathrm{SO}_{2}^{\prime} \\
\mathrm{SO}_{2}^{\prime} \rightarrow \mathrm{SO}_{2}^{\prime \prime}\left(+M \rightarrow \mathrm{SO}_{2}\right) \\
\mathrm{SO}_{2}^{\prime}+\mathrm{SO}_{2} \rightarrow \mathrm{SO}_{2}+\mathrm{SO}_{2}
\end{gathered}
$$




$$
\begin{gathered}
\mathrm{SO}_{2}^{\prime}+\mathrm{N}_{2} \rightarrow \mathrm{SO}_{2}+\mathrm{N}_{2} \\
\mathrm{SO}_{2}^{\prime}+\mathrm{O}_{2} \rightarrow \mathrm{SO}_{2}+\mathrm{O}_{2} \\
\mathrm{SO}_{2}^{\prime}+\mathrm{O}_{2} \rightarrow \mathrm{SO}_{4} \\
\mathrm{SO}_{4}+\mathrm{SO}_{2} \rightarrow 2 \mathrm{SO}_{3} \\
\mathrm{SO}_{4}+\mathrm{O}_{2} \rightarrow \mathrm{SO}_{3}+\mathrm{O}_{3} \\
\mathrm{SO}_{3}+\mathrm{H}_{2} \mathrm{O} \rightarrow \mathrm{H}_{2} \mathrm{SO}_{4}
\end{gathered}
$$

It is seen from these equations that the postulated mechanism leads to sulfuric acid vapor. the amount of this vapor being proportional to the initial sulfur dioxide concentration. The sulfuric acid molecules interact with each other and with water molecules thereby forming the nuclei detected in the experiments. The number of nuclei thus depends on the sulfur dioxide concentration and on the amount of water vapor. The actual relationship between the number of nuclei and these two parameters must be determined experimentally and is given by the cmpirical equation (2).

It would be of interest now to compare the present data with results of other investigations. Results of direct measurements of the number of nuclei formed in sulfur dioxide-air mixtures were reported by $\mathrm{Cox}$ and Penkett (1970), Cox (1974), Kocmond et al. (1973), Quon et al. (1971), and by Renzetti and Doyle (1960). The present results can be compared with those obtained by Renzetti and Doyle (1960) and Kocmond et al. (1973). The number of nuclei obtained by Renzetti and Doyle for $0.24 \mathrm{ppm}$ sulfur dioxide at $50 \%$ r.h. ranged from $5 \times 10^{4}$ to $8 \times 10^{5}$ nuclei $\mathrm{cm}^{-3}$. For this sulfur dioxide concentration and relative humidity the number of nuclei calculated from equation (2) is $2 \times 10^{5}$ nuclei $\mathrm{cm}^{-3}$. Hence, the value obtained in the present study lies within the spread of Renzetti and Doyle's data. The amounts of nuclei measured by Kocmond et al. were two to four times higher than the values obtained in this investigation. The reason for this is unclear. The discrepancy between the two results might possibly be due to the fact that the present data were obtained from flow type experiments while Kocmond et al. performed their measurements in static type experiments.

The results of Cox and Penkett (1970), Quon et al. (1971), and Cox (1974) cannot be compared with the present data. Cox and Penkett did not report the humidity in their results; Quon et al. performed measurements before the maximum amounts of nuclei were produced. The data obtained by Cox were obtained for much higher initial sulfur dioxide concentrations $(5-1000 \mathrm{ppm})$ than those used in the present study $(0.2-1 \mathrm{ppm})$.

Some indirect comparisons with other existing data can be made to confirm the present results. Gerhard and Johnstone (1955) placed sulfur dioxide-air mixtures in a $0.008 \mathrm{~m}^{3}$ Lucite chamber irradiated by a sun lamp and collected the sulfuric acid formed. If it is assumed that most of the nuclei formed in the present study were composed of sulfuric acid then the amount of sulfuric acid collected by Gerhard and

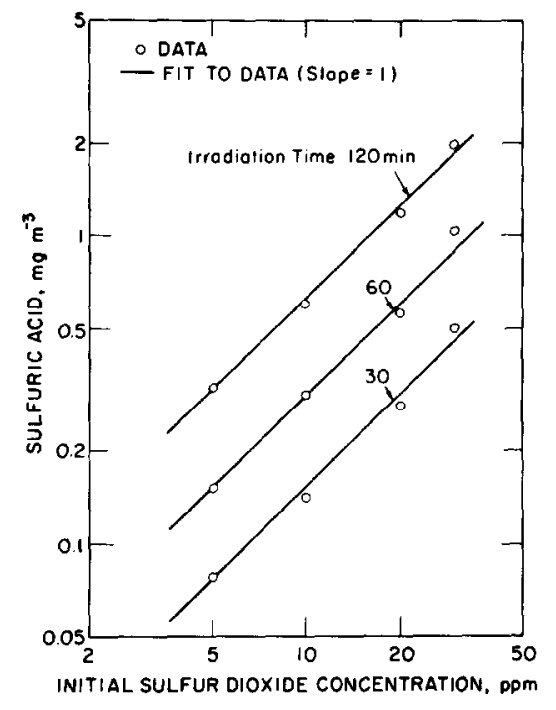

Fig. 7. Formation of sulfuric acid in sulfur dioxide-air mixtures [Data from Gerhard and Johnstone (1955)].

Johnstone should vary with the initial $\mathrm{SO}_{2}$ concentration in the same manner as the number of nuclei. The variation of sulfuric acid with the initial sulfur dioxide concentration, as reported by Gerhard and Johnstone, is presented in Fig. 7. This figure shows that similar to the number of nuclei formed (see equation 2). the amount of sulfuric acid collected varies linearly with the initial sulfur dioxide concentration.

Renzetti and Doyle (1960) measured the amount of light scattered from a sulfur dioxide-air mixture undergoing photochemical reaction. Their data are reproduced in Fig. 8. Although there is considerable spread in Renzetti and Doyle's data, the amount of

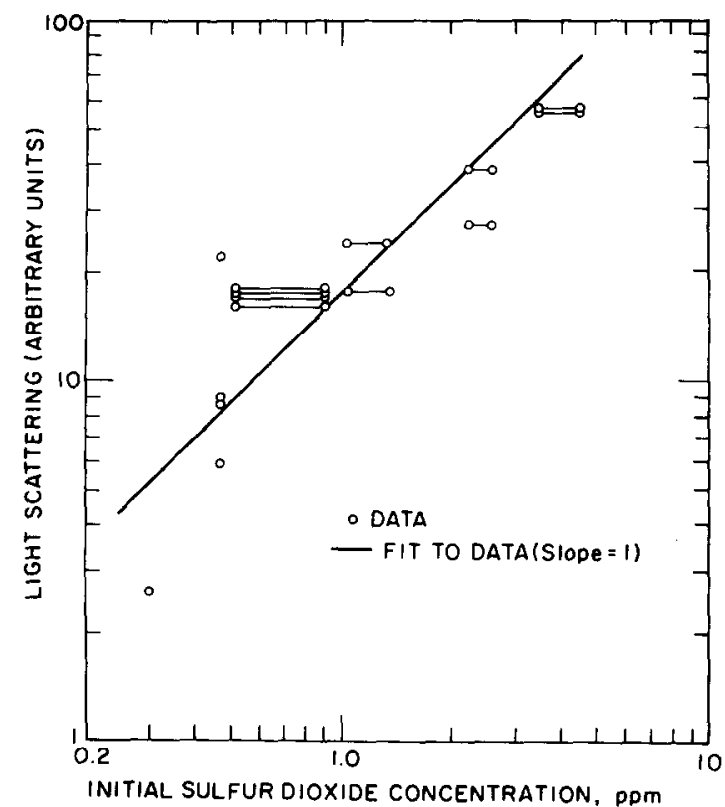

Fig. 8. Amount of light scaltered from sulfur dioxide air mixtures [Data from Renzetti and Doyle (1960)]. 
light scattered (which is proportional to the number of nuclei formed) appears to vary linearly with the initial sulfur dioxide concentration. further supporting the validity of equation (2).

The information avaliable regarding the effect of the relative humidity on the number of nuclei is conflicting. Renzetti and Doyle observed that the amount of light scattered increased with relative humidity. Cox (1974) also reported that the number of nuclei increased with humidity. Katz and Gale (1971) observed an increase in the conversion rate of sulfur dioxide to sulfur trioxide (or sulfuric acid) as the humidity was increased. These results thus support the present data which show an increase in nucleation rate as well as the number of nuclei formed with relative humidity. In contrast to these results, Gerhard and Johnstone (1955) found that the sulfur dioxide conversion rate did not change with relative humidity. The results of Quon et al. (1971) indicated that the number of nuclei formed was independent of relative humidity. The data obtained by Kocmond et al. (1973) did not show any dependence of the conversion rate of sulfur dioxide on relative humidity. Kocmond et al. found, however, that the rate of change of the total volume of the aerosols depended on relative humidity. Because of the conflicting evidence, the effect of humidity on the nuclei formation in sulfur dioxideair mixtures would merit further studies.

Acknowledgement-This work was supported by the Environmental Protection Agency.

\section{REFERENCES}

Cox R. A. (1974) Particle formation from homogeneous reactions of sulfur dioxide and nitrogen dioxide. Tellus 26. $235-240$.
Cox R. A. and Penkett S. A. (1970) The photooxidation of sulfur dioxide in sunlight. Atmospheric Environment 4, 425-433.

Gerhard F. R. and Johnstone H. F. (1955) Photochemical oxidation of sulfur dioxide in air. Ind. Engng Chem. 47, 972-976.

Groblicki P. J. and Nebel G. J. (1971) The photochemical formation of aerosols in urban atmospheres. In Chemical Reactions in Urhan Atmospheres (Edited by Tuesday C. S.), pp. 241-264. American Elsevier, N.Y.

Katz M. and Gale S. B. (1971) Mechanism of photooxidation of sulfur dioxide in atmosphere. Proceedings 2nd International Clcan Air Congress (Edited by Englund H. M. and Beery W. T.), pp. 336-343. Academic Press, N.Y.

Kocmond W. C., Kittleson D. B., Yang J. Y. and Demerjian K. L. (1973) Determination of the formation mechanisms and compositions of photochemical aerosols. Calspan Corporation, Buffalo, New York. 1st Annual Summary Report. Prepared for the Environmental Protection Agency, Durham, North Carolina and Coordinating Research Council, N.Y.

Leighton P. A. (1961) Photochemistry of Air Pollution, pp. 235-237. Academic Press, N.Y.

Quon J. E.. Siegel R. P. and Hulbert H. M. (1971) Particle formation from photooxidation of sulfur dioxide in air. Procesedings 2nd International Clear Air Conaress (Edited by . Englund H. M. and Beery W. T.), pp. 330-335. Academic Press, N.Y.

Renzetti N. A. and Doyle G. J. (1960) Photochemical aerosol formation in sulfur dioxide-hydrocarbon systems. Int. J. Air Pollut. 2, 327-345.

Shen C. H. and Springer G. S. (1975a) Ozone and particulate formation in photochemical reactions. Fluid Dynamics Laboratory Publication No. 75-1, Department of Mechanical Engineering. The University of Michagan.

Shen C. H. and Springer G. S. (1975b) Photochemical particulate formation in cyclohexene-nitrogen dioxide-air mixtures. Environ. Sci. Technol. (submitted).

Shen C. H., Springer G. S. and Stedman D. H. (1975) Photochemical ozone formation in cyclohexene-nitrogen dioxide-air mixtures. Environ. Sci. Technol. (submitted). 